patterns of invasive pneumococcal disease. Gidding describes population serosurveillance and Australia's national serosurveillance program, in particular, how it is used to estimate levels of immunity to vaccinepreventable diseases. The issue concludes with two short reports of recent publications by the National Centre for Immunisation Research and Surveillance of Vaccine Preventable Diseases (NCIRS), Vaccine-Preventable Diseases and Vaccination Coverage in Australia, 19992000 and Immunisation Coverage: Australia 2001.

\section{REFERENCES}

1. Hall R. Notifiable diseases surveillance, 1917 to 1991. Commun Dis Intell 1993;17:226-36.

2. McIntyre P, Amin J, Gidding H, et al. Vaccine preventable diseases and vaccination coverage in Australia, 1993-1998. Commun Dis Intell 2000;24 (Suppl):S1-S83.

3. Orenstein WA. Pertussis in adults: epidemiology, signs, symptoms, and implications for vaccination. Clin Infect Dis 1999;28 (Suppl):S147-S150.

4. Robertson PW, Goldberg H, Jarvie BH, Smith DD, Whybin LR. Bordetella pertussis infection: a cause of persistent cough in adults. Med J Aust 1987;146(10):522-5.

5. Blogg S, Trent M. Doctor's notifications of pertussis. NSW Public Health Bull 1998;9:53-4
6. Allen CJ, Ferson MJ. Notification of infectious diseases by general practitioners: a quantitative and qualitative study. Med J Aust 2000;172:325-8.

7. Poynten M, Hanlon M, Irwig L, Gilbert GL. Serological diagnosis of pertussis: evaluation of $\operatorname{IgA}$ against whole cell and specific Bordetella pertussis antigens as markers of recent infection. Epidemiol Infect 2002;128:161-7.

8. Thomas PF, McIntyre PB, Jalaludin BB. Survey of pertussis morbidity in adults in western Sydney. Med J Aust 2000;173:74-6.

9. Sullivan EA, Chey T, Nossar V. A population-based survey of immunisation coverage in children aged 2 years and younger in New South Wales. J Paediatr Child Health 1998;34:342-5.

10. MacIntyre CR, Nolan T. Attitudes of Victorian vaccine providers to pertussis vaccine. Med J Aust 1994;161:295-9.

11. Ntezayabo B, De Serres G, Duval B. Pertussis resurgence in Canada largely caused by a cohort effect. Paediatr Infect Diseases J 2003;22:22-7.

12. Torvaldsen S, Simpson JM, McIntyre PB. Effectiveness of pertussis vaccination in New South Wales, Australia, 19961998. Eur J Epidemiol 2003;18:63-9.

13. McIntyre P, Elliot E, Morris A, Ridley G et al. Hospitalised pertussis in infancy. Australian Paediatric Surveillance Unit. 9th Annual Report. Elliot E, Ridley G, Rose D, Morris A, Redmond D, Fowler J ( editors). Sydney:APSU, 2002.

14. NSW HCW immunisation web address: www.health.nsw. gov.au/fcsd/rmc/cib/circulars/2001/cir2001-91.pdf

\title{
HAS PERTUSSIS INCREASED IN NSW OVER THE PAST DECADE? AN EVALUATION USING HOSPITALISATION AND MORTALITY DATA VERSUS NOTIFICATIONS 1988-2002
}

\author{
Rob Menzies, Han Wang and Peter McIntyre \\ National Centre for Immunisation Research and \\ Surveillance of Vaccine Preventable Diseases \\ University of Sydney, Westmead
}

Pertussis, or whooping cough, notifications, and deaths declined dramatically after the introduction of mass vaccination in the 1950 s, to the extent that many states stopped collecting notifications. ${ }^{1}$ However, since 1990, notification rates have increased noticeably from the record low levels seen in the 1970s and 1980s in all Australian states and territories, including NSW. ${ }^{1}$ A number of factors, other than a true increase in the underlying incidence of pertussis, may account for this. ${ }^{2,3}$ These factors include: improved surveillance, the introduction of direct notification of cases by laboratories, and the introduction of additional means of laboratory diagnosis such as serology and nucleic acid testing. ${ }^{2}$ In contrast to notifications, criteria for coding hospital separations or deaths due to pertussis are less likely to have been influenced by these changes, ${ }^{3-7}$ thus providing a data source that is more consistent over time to evaluate for evidence of a resurgence in pertussis. This article compares age-specific hospital separations, notifications, and deaths due to pertussis in NSW, prior to and including the period of changes to the notification procedure that followed introduction of the NSW Public Health Act 1991.

\section{METHODS}

\section{Data sources}

NSW hospital separations with a primary diagnosis code of pertussis (ICD-9, 033; ICD-10, A37) were available from 1988-1989 to 2000-2001 from the NSW Inpatients Statistics Collection (ISC) through the Health Outcomes Information Statistical Toolkit (HOIST), and the yearly total for 2001-2002 from the NSW Health Information Exchange. Notifications were available from 1992- 2002 from the Notifiable Disease Database, via HOIST.

Deaths reported with a principal or underlying cause of pertussis (ICD-7, 056; ICD-8, 033; ICD-9, 033; ICD-10, A37) were obtained from the Australian Bureau of Statistics via HOIST. Death data were available from 19642000. Deaths that occurred in 2001 were ascertained by a 
FIGURE 1

HOSPITAL SEPARATION RATES FOR PERTUSSIS, NSW, FOR FINANCIAL YEARS 1988-89 TO 2001-02

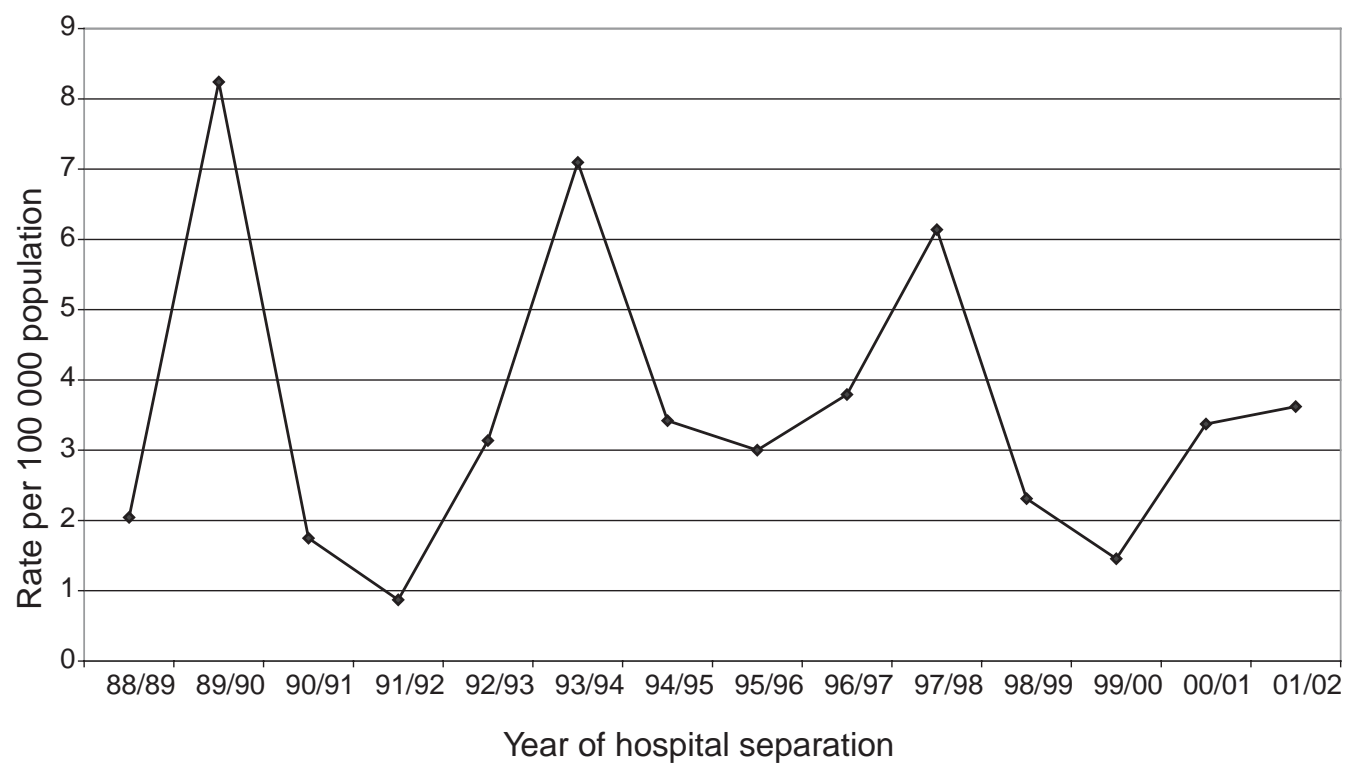

Sources: NSW Inpatients Statistics Collection and ABS population estimates (HOIST), Centre for Epidemiology and Research, and the NSW Health Information Exchange, NSW Department of Health.

request to public health units via the Communicable Diseases Network, Australia. Pertussis notifications were available from 1992 to 2002 from the Notifiable Disease Database via HOIST.

Immunisation coverage estimates for NSW from 1989 to 1995 were available from several published sources. ${ }^{8-10}$ From 1997 to 2002, coverage for NSW was calculated from Australian Childhood Immunisation Register (ACIR) data, maintained by the Health Insurance Commission and published annually in Communicable Disease Intelligence. Coverage was calculated for three-month cohorts of children aged 12 months. Coverage was adjusted upwards by 2.7 per cent to correct for under-reporting, using estimates from a recent study. ${ }^{11}$

\section{Statistical methods}

For analysis by age, records were grouped according to critical ages for expected acquisition of vaccine-induced immunity. These ages corresponded to the time of scheduled vaccine doses for diphtheria-tetanus-pertussis (DTP) vaccine: $0-2$ months (0-1 dose); 3-4 months (1-2 doses); 5-6 months (2-3 doses); 7-11 months (3 doses); 1-4 years (3-5 doses); 5-9 years (1-5 years after last dose); 10-14 years (5-9 years after last dose) and 15 years and over (10 or more years after last dose). Notification and hospitalisation rates were calculated using ABS midyear estimated residential populations as rates per 100,000.

Linear regression was used to test for the significance of trends over time and to estimate their magnitude. Models included the monthly notification or separation rate per
100,000 population as the dependent variable, and the month of onset or separation as the independent variable. Given that epidemics occur in cycles every three to four years, the likelihood of detecting trends over time is influenced by the stages of the cycle in the first and last years included in the analysis. Notifications from 19921993 were excluded from this analysis, so that the period included in the model would begin and end at the same stage of the epidemic cycle, including three epidemic periods (1993-1994, 1997-1998, and 2000-2001). Analysis was carried out in SAS 8.2. ${ }^{12}$

\section{RESULTS}

\section{Descriptive analysis}

Overall hospital separation and notification rates Figure 1 shows the separation rate per 100,000 total population and Figure 2 shows the annual notification rates per 100,000 population (using different scales). Separation data are shown for all available consecutive years (from 1988-1989 to 2000-2001). Notification data are shown only from 1992, as this was the first complete year of mandatory laboratory notification. Separation data cover four epidemic periods (1989-1990, 1993-1994, 1997-1998, and 2000-2001), while notification data include only the last three periods. Notification and hospitalisation rates reach epidemic peaks at similar times. However, the height of successive epidemic peaks for separations became progressively lower with each epidemic, while the peak notification rate progressively increased. 


\section{FIGURE 2}

NOTIFICATION RATES FOR PERTUSSIS, NSW, FOR THE FINANCIAL YEARS 1992-93 TO 2001-02

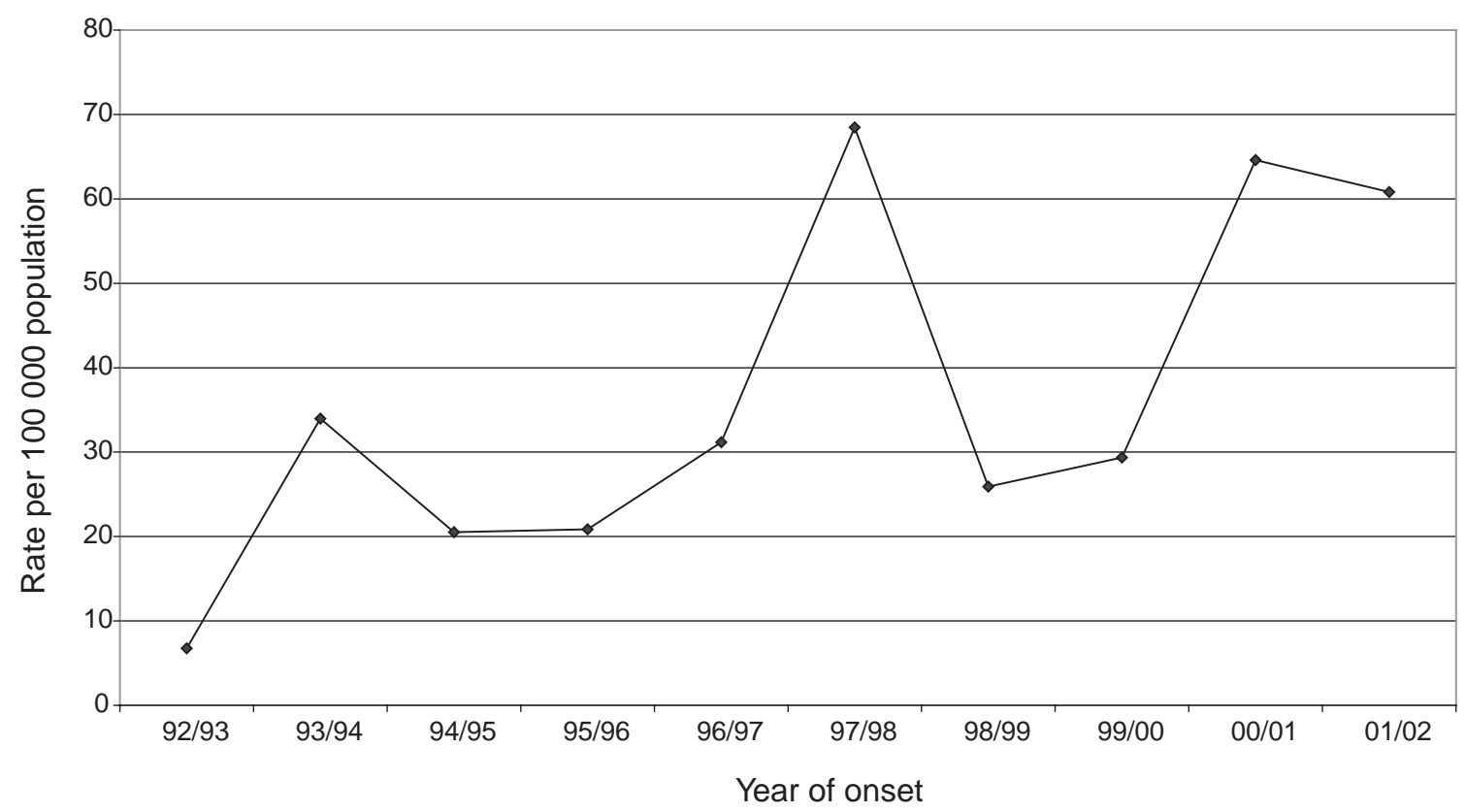

Sources: Communicable Diseases Branch, NSW Notifiable Disease Database and ABS population estimates (HOIST), Centre for Epidemiology and Research, NSW Department of Health.

\section{FIGURE 3}

INITIATIVES IN VACCINATION, AND DIPHTHERIA-TETANUS-PERTUSSIS (DTP) VACCINATION COVERAGE, NSW, 1988-2001

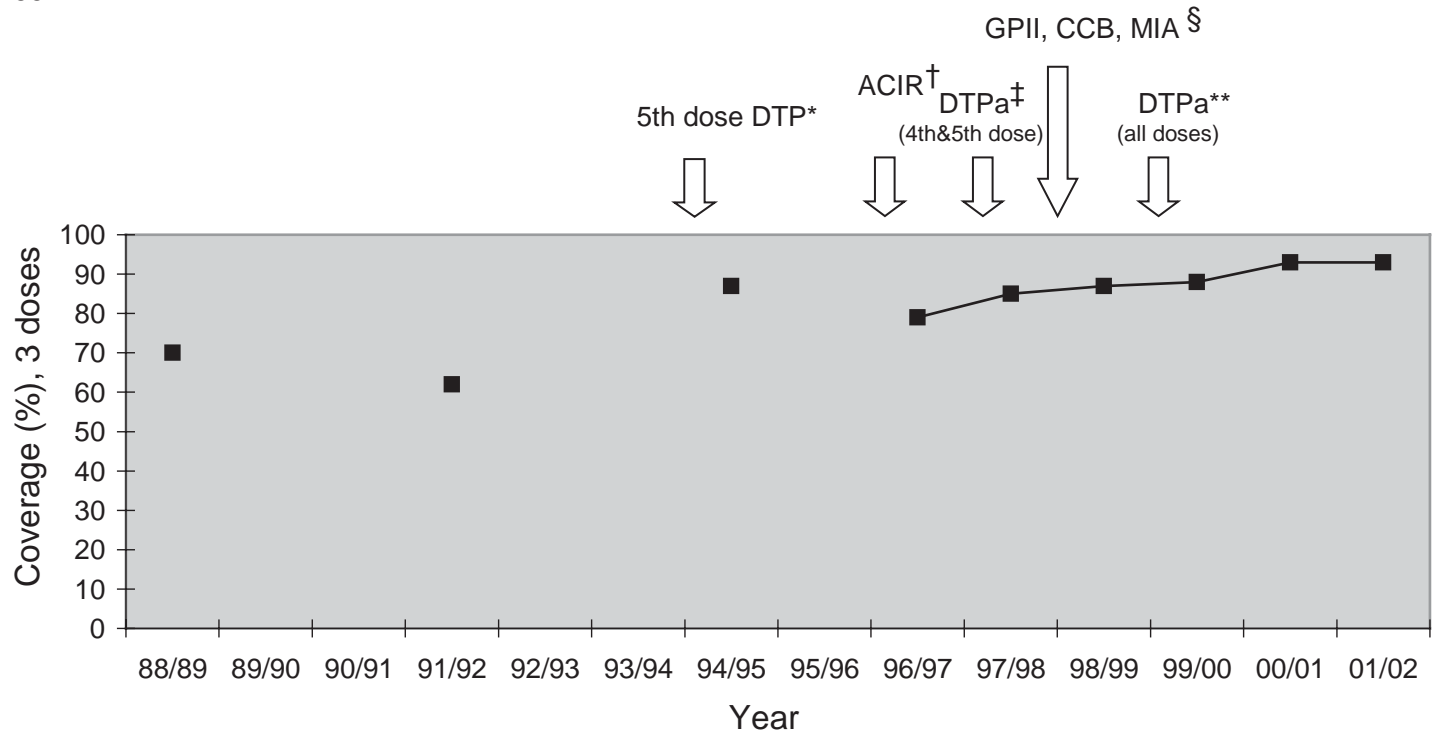

* 5 th dose of DTP introduced into standard vaccination schedule

† Introduction of Australian Childhood Immunisation Register (ACIR)

‡ DTP with acellular pertussis component approved for use in 4th and 5 th doses

$\S$ Introduction of General Practice Immunisation Incentive, Child Care Benefit and Maternity Immunisation Allowance

**DTP with acellular pertussis component approved for use in all doses

Sources: References 8-10, ACIR. 


\section{Vaccine coverage}

Coverage estimates for diphtheria-tetanus-pertussis (DTP) vaccine are displayed in Figure 3. The first data point shown, for 1988-1989, is derived from the 19891990 ABS survey, which estimated that 70 per cent of NSW children aged 0-6 years were fully immunised for pertussis. ${ }^{8}$ The second data point shown, for 1991-1992, is derived from a 1992 cross-sectional survey of NSW residents. This household survey, primarily designed to validate child health records, found an even lower estimated coverage of 62 per cent for the primary course of three doses in children aged 7-24 months. ${ }^{9}$ By the time of the 1995 ABS survey, shown as the third data point, 87 per cent of NSW children aged one year were estimated to be fully immunised for DTP. ${ }^{10}$ Coverage data from the ACIR for DTP for children aged 12-24 months were significantly under-reported in the early period of operation of the ACIR, ${ }^{11}$ such that initial reported coverage of 77 per cent was lower (almost certainly falsely lower) than the 1995 ABS estimates. Overall, coverage for three doses of pertussis vaccine, according to the ACIR, and adjusted for under-reporting, increased from 79 per cent in 1997 to 94 per cent in 2001.

Figure 3 also shows the timing of various key initiatives to improve immunisation coverage and vaccine-acquired immunity to pertussis in particular. These key initiatives include the introduction of a fifth dose at 4-5 years in 1994, the change to acellular vaccines for booster doses in early 1998, and for all doses by mid 1999 .

Age-specific hospital separation and notification rates In Figure 4, separation rates are shown divided into four age groups to show the trends over time in those under one year of age. The most striking change in Figure 4 is the downward trend in separation rates among infants aged 5-6 months. This trend is progressively evident from 1994-1995 when it coincides with improved vaccine coverage in infancy, ${ }^{10}$ subsequently remaining constant with the introduction of acellular vaccines, shown in Figure 3. There is a less marked but perceptible fall in separation rates among 7-11-month-old infants. In contrast, no change is seen in separation rates for infants 0-2 months of age, while a minor decrease is seen in those aged 3-4 months.

\section{Deaths}

Recorded deaths from pertussis are shown in Table 1. In the first time period (1964-1973), 47 per cent of pertussis deaths were recorded in those aged five months or older. In contrast, between 1974 and 2001, a much lower proportion (nine per cent) was aged five months or more (Table 1). There have been no deaths reported in the age group five months or older since 1984.

\section{FIGURE 4}

PERTUSSIS HOSPITAL SEPARATIONS BY AGE GROUP, NSW, FOR FINANCIAL YEARS 1988-89 TO 2000-01

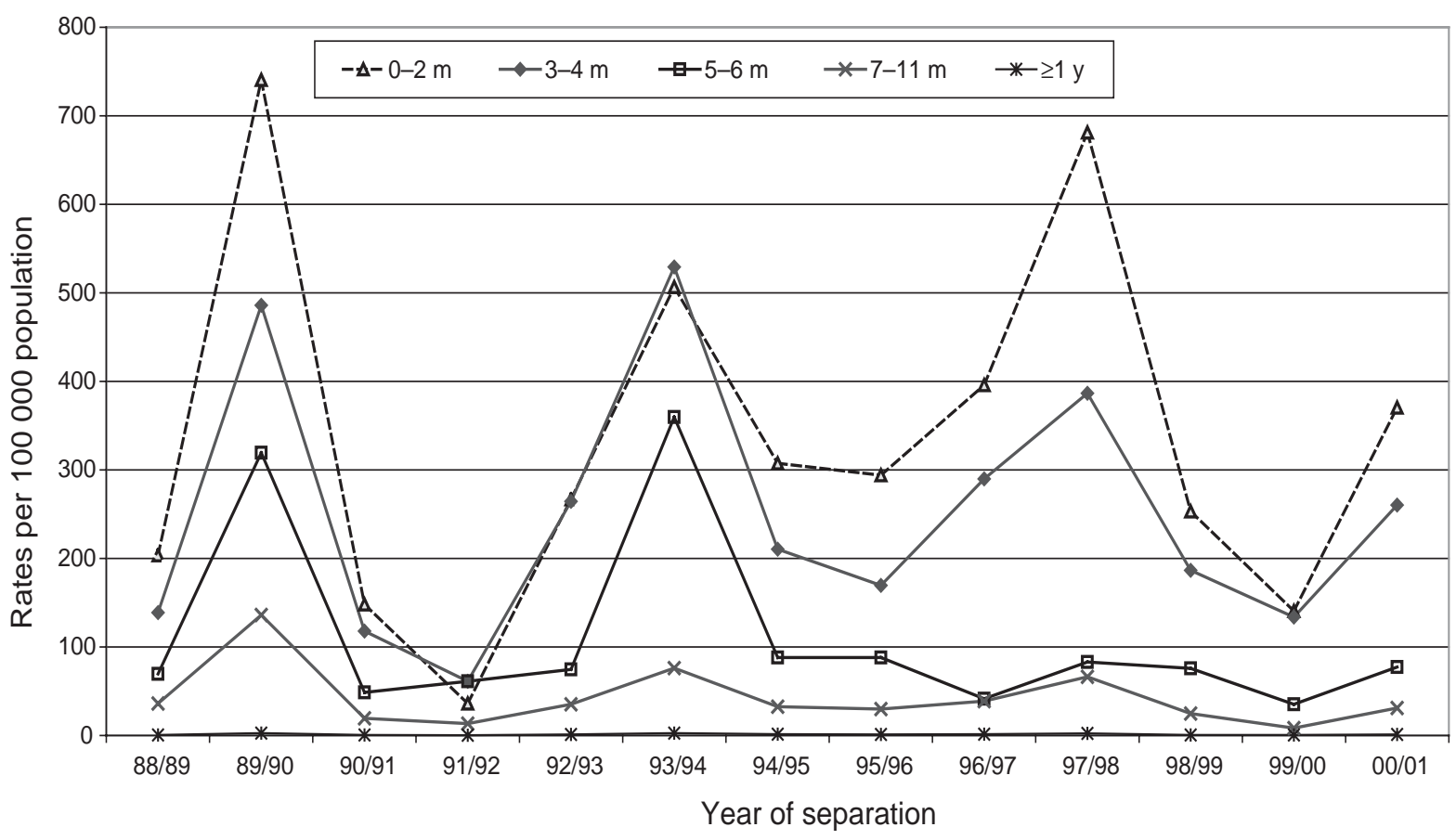

Source: NSW Inpatients Statistics Collection and ABS population estimates (HOIST), Centre for Epidemiology and Research, NSW Department of Health. 


\section{Linear regression modelling}

The analysis of trends in monthly pertussis separation and notification rates by age-group, using linear regression modelling, is summarised in Table 2. For all ages combined, modelling detected no statistically significant increasing or decreasing trend in monthly separation rates over the three years from July 1988 to June 2001. In contrast, notification rates increased significantly. The rate of increase in monthly notification rates in Table 2 corresponds to a total increase of 170 per cent between July 1994 and June 2002, which is in keeping with the trends shown in Figure 2.

When analysed by smaller age groups, there was no significant increase or decrease in separation rates for those infants aged between 0-4 months, although there was an increase in notification rates for 0-2-month-old infants, which was almost significant at the $P<0.05$ level. In contrast, there was a significant decrease in separation rates in the four age groups (5-6 months, 7-11 months, 1-4 years, and 5-9 years) between five months and nine years, but no significant decrease in notifications in those age groups. In the 10-14 year age group, despite a large and highly significant increase in notifications, there was no increase in separation rates. In contrast to the 10-14 year age group, a significant increase was detected among those aged over 15 years for both separations and notifications.

\section{TABLE 1}

DEATHS DUE TO PERTUSSIS, NSW, 1964-2001

\begin{tabular}{|lrrc|}
\hline $\begin{array}{l}\text { Period } \\
\text { (years) }\end{array}$ & \multicolumn{2}{c}{$\begin{array}{c}\text { Age of patient } \\
\text { (months) }\end{array}$} & $\begin{array}{c}\text { Total no. } \\
\text { of deaths }\end{array}$ \\
\hline & $\mathbf{0}$ & $\geq 5$ & \\
$1964-73$ & 10 & 9 & 19 \\
$1974-83$ & 2 & 1 & 3 \\
$1984-93$ & 3 & 0 & 3 \\
$1994-01$ & 5 & 0 & 5 \\
Total & $\mathbf{2 0}$ & $\mathbf{1 0}$ & $\mathbf{3 0}$ \\
\hline
\end{tabular}

Sources: ABS mortality data (HOIST), Centre for Epidemiology and Research; and the public health units (via the Communicable Diseases Network, Australia).

\section{DISCUSSION}

Hospitalisation and notification data give very different pictures of pertussis epidemiology, ${ }^{3}$ as the former is heavily weighted towards infants under the age of 12 months and cases of severe disease. ${ }^{4,7}$ Overall, the hospitalisation rate in NSW did not increase over the past 13 years, while the notification rate increased substantially after 1992. When examined by age, those age groups with the highest levels of coverage (five months to nine years) showed a decreased rate of hospitalisation during that

\section{TABLE 2}

CHANGES IN MONTHLY SEPARATION RATES PER 100,000 POPULATION BETWEEN JULY 1988 AND JUNE 2001, AND IN NOTIFICATION RATES BETWEEN JULY 1993 AND JUNE 2002; RESULTS OF LINEAR REGRESSION MODELLING, NSW

\begin{tabular}{|c|c|c|c|c|c|c|}
\hline \multirow{2}{*}{$\begin{array}{l}\text { Age } \\
\text { months or } \\
\text { years }\end{array}$} & \multicolumn{3}{|c|}{ Separations } & \multicolumn{3}{|c|}{ Notifications } \\
\hline & \multicolumn{2}{|c|}{$\begin{array}{c}\text { Adjusted initial } \\
\text { monthly frequency }\end{array}$} & \multirow[t]{2}{*}{$\begin{array}{l}\text { Change in } \\
\text { monthly rate, } \\
\text { July 1988- } \\
\text { June 2001' }\end{array}$} & \multicolumn{2}{|c|}{$\begin{array}{c}\text { Adjusted initial } \\
\text { monthly frequency }\end{array}$} & \multirow[t]{2}{*}{$\begin{array}{l}\text { Change in } \\
\text { monthly rate, } \\
\text { July 1993- } \\
\text { June } 2002^{\dagger}\end{array}$} \\
\hline & $N$ & Rate & & $N$ & Rate & \\
\hline $0-2 \mathrm{~m}$ & 5.9 & 27.4 & 0.007 & 3.5 & 15.7 & $0.106^{\ddagger}$ \\
\hline $3-4 \mathrm{~m}$ & 3.1 & 21.5 & -0.010 & 1.7 & 11.5 & 0.039 \\
\hline $5-6 \mathrm{~m}$ & 2.0 & 13.9 & $-0.062^{\S}$ & 1.4 & 9.5 & -0.030 \\
\hline $7-11 \mathrm{~m}$ & 1.9 & 5.2 & $-0.021^{\S}$ & 2.7 & 7.3 & -0.015 \\
\hline $1-4 \mathrm{yr}$ & 3.4 & 1.0 & $-0.003^{\prime \prime}$ & 15.7 & 4.5 & -0.011 \\
\hline $5-9 \mathrm{yr}$ & 3.5 & 0.85 & $-0.005^{\pi}$ & 37.9 & 8.9 & $-0.033^{* *}$ \\
\hline $10-14 \mathrm{yr}$ & 0.88 & 0.21 & $<0.0001$ & 8.8 & 2.1 & $0.143^{\pi}$ \\
\hline $15+y r$ & 0.11 & 0.003 & $0.0003 \pi$ & 24.7 & 0.5 & $0.025^{\pi}$ \\
\hline Total & 19.5 & 0.34 & -0.0005 & 91.1 & 1.5 & $0.027 \pi$ \\
\hline
\end{tabular}

* Linear regression model intercept. Rates equal number per month per 100, 000 population

† Linear regression model slope. $P>0.1$ unless otherwise stated.

$\ddagger P=0.06 \S P=0.01$ II $P=0.03$ I $P<0.0001$ ** $P=0.09$

Sources: NSW Inpatients Statistics Collection and ABS population estimates (HOIST), Centre for Epidemiology and Research; the NSW Health Information Exchange; and the Notifiable Disease Database, NSW Department of Health. 
period, in contrast to notifications, where there was no significant decrease in any age group. However, in adults (over the age of 15 years) both hospitalisation and notification data showed significant increases, suggesting that the observed increase in notifications in this age group reflected a real increase in underlying incidence and not simply increased detection from diagnostic testing. ${ }^{2}$

During the mid-to-late 1990s, a series of immunisation initiatives were introduced in Australia, which were intended to decrease the incidence of, and morbidity from, pertussis and other vaccine-preventable diseases (Figure 3). ${ }^{1,11}$ In 1994, a fifth dose of DTP at 4-5 years of age was introduced into the recommended schedule. This extra dose was intended to reduce pertussis transmission in school-aged children. In 1997, DTP with an acellular pertussis component (DTPa) was recommended for the fourth and fifth doses. The aim was to increase the acceptability of the vaccine to parents by reducing its reactogenicity, thus leading to improved coverage. In 1999, DTPa was made available for all scheduled doses. ${ }^{1}$ In addition, from 1998, three new initiatives, the General Practice Immunisation Incentive, and linkage of full immunisation to the Maternity Immunisation Allowance and the Child Care Benefit, were introduced with the aim of improving coverage for all vaccines. Linkage to the receipt of the Maternity Immunisation Allowance and the Child Care Benefit has been shown to have a positive impact on parents' decisions to immunise their children. ${ }^{11}$

Although the available data on vaccination coverage used in this article came from various sources using different methodology and measures, they still provide evidence of a considerable increase in coverage as a consequence of those initiatives.

There has been relatively little change in methods of treatment or management of pertussis over the past 15 years that is likely to affect the number of recorded separations. ${ }^{3,7}$ It is likely that the reduction in hospitalisation rates seen in those aged five months to nine years is related to improvements in vaccination coverage. In contrast, the substantial and increasing proportion of pertussis notifications in children over nine years of age is likely to relate to the increasing availability of serological diagnosis. This increase, together with mandatory laboratory reporting of notifiable diseases, may explain changes in notifications among this age group. However, the proportion of pertussis separations that were aged 15 or more years also increased, from two per cent in 1988-1989 to 12 per cent in 2000-2001. Separations coded as pertussis represent more serious cases, where there is likely to be greater clinical evidence of pertussis. This increase is thus likely to be less biased by improvements in diagnosis, suggesting a real increase in incidence in adults. In contrast, among those too young to have received more than two doses of pertussis vaccine (less than five months of age) there was no evidence of change in either notifications, hospitalisations, or deaths over the period 1988-1989 to 2001-2002.

\section{CONCLUSION}

This analysis of hospitalisation and death data provides a more complete view of the evolving epidemiology of pertussis in NSW. There is evidence that improvements in immunisation coverage and changes to the immunisation schedule over the past five to seven years have had an effect on serious pertussis morbidity in the age groups with the highest immunisation coverage. In contrast, no significant reduction in the incidence of hospitalisation was found among babies too young to have received three doses of pertussis vaccine. This finding and the evidence of increased hospitalisation among adults suggest that adults are acting as a reservoir for disease transmission to infants. Further measures to control pertussis will need to focus both on reducing the burden of disease in adolescents and adults and on protecting infants too young to be immunised by current regimens.

\section{REFERENCES}

1. McIntyre P, Gidding H, Gilmour R, Lawrence G, Hull B, Horby $\mathrm{P}$, et al. Vaccine preventable diseases and vaccination coverage in Australia, 1999-2000. Commun Dis Intell 2002;26 Suppl:1-111.

2. Poynten M, Irwig L, Hanlon M, Gilbert GL. Serological diagnosis of pertussis: evaluation of IgA against whole cell and specific Bordetella pertussis antigens as markers of recent infection. Epidemiol Infect 2002;128:161-7.

3. Scheil W, Cameron S, Roberts C, Hall R. Pertussis in South Australia 1893 to 1996. Commun Dis Intell 1998;22:76-80.

4. Sutter RW, Cochi SL. Pertussis hospitalizations and mortality in the United States, 1985-1988: evaluation of the completeness of national reporting. JAMA 1992;267:386-91.

5. Shaikh R, Guris D, Strebel PM, Wharton M. Under-reporting of pertussis deaths in the United States: Need for improved surveillance. Pediatrics 1998;101:323-5.

6. Williams GD, Matthews NT, Choong RKC, Ferson MJ. Infant pertussis deaths in New South Wales 1996-1997. Med J Aust 1998;168:281-3.

7. Herzig P, Hartmann C, Fischer D, et al. Pertussis complications in Germany-3 years of hospital-based surveillance during the introduction of acellular vaccines. Infection 1998;26:227-31.

8. 1989-90 National Health Survey. Children's Immunisation, Australia. Canberra: Australian Bureau of Statistics, 1991. Catalogue No. 4379.0.

9. Sullivan EA, Chey T, Nossar V. A population-based survey of immunisation coverage in children aged 2 years and younger in New South Wales. J Paediatr Child Health 1998;34,342-5.

10. Children's Immunisation Australia. Canberra: Australian Bureau of Statistics, 1995. Catalogue No. 4352.0.

11. Hull B, Lawrence G, MacIntyre CR, McIntyre P. Immunisation Coverage: Australia 2001. Canberra: Commonwealth of Australia, 2002.

12. SAS version 8 [computer program]. Win98. Cary, NC: SAS Institute Inc., 1999. 